\section{Logo Therapy Conselling for Gifted Children With Post Trauma Stress Symptoms Due to Rob Disaster and Flood}

\author{
Rini Sugiarti; Erwin Erlangga \\ Fakultas Psikologi, Universitas Semarang \\ e-mail: riendoe@usma.ac.id, erwin erlangga@usm.ac.id
}

Journal PSIKODIMENSIA

Volume 17, No. 2, Juli - Desember 2018

ISSN cetak : 1411-6073

ISSN online : 2579-6321

DOI 10.24167/psidim.v17i2.1658

\begin{abstract}
The purpose of this study was to help gifted children who experience symptoms of posttraumatic stress so that the potential of gifted children is not lost in vain. In this globalization era, the causes of trauma to individuals are increasing. Individual counseling with logotherapy techniques is considered appropriate to help gifted children who experience symptoms of posttraumatic stress because logotherapy counseling can help gifted children get the meaning of life. This research method was quasiexperimental. The sample in this study were students who experienced posttraumatic stress due to flooding and rob in the Genuk, Sayung, Wringjajar, Morosari and Kalisari regions,Semarang. The total partisipant 10 gifted children. The results of the study showed an increase in the meaning of life of gifted children after being given individual counseling. The hypothesis which states counseling individuals with logotherapy techniques to increase the meaning of life of gifted children who are traumatized by flooding and rob is acceptable.
\end{abstract}

Keywords: Post Traumatic Stress, Gifted children, Rob disaster and Flood

\section{PENDAHULUAN}

Peristiwa traumatik bisa terjadi pada siapa saja. Berbagai peristiwa traumatik tersebut berpotensi sebagai penyebab munculnya masalah psikologis yaitu trauma bagi korbannya. Adapun penyebab trauma pasca traumatik antara lain, bencana alam, kasus pelecehan seksual, lingkungan yang sering konflik/kerusuhan, keluarga tidak harmonis (brokenhome), dan kecelakaan. Bencana alam menjadi penyebab trauma pada diri seseorang, seperti yang dikemukakan oleh Wagner dan Mcmahon (2004), hasil penelitiannya pada anak yang mengalami bencana memang mengalami gejala stress pasca trauma.
Wagner dan Mcmahon, (2004), menganggap gejala stress pasca trauma sebagai sebuah gejala yang timbul akibat adanya kesenjangan antara realitas dan ideal, antara keinginan dan kenyataan, antara tantangan dan kemampuan, dan antara peluang dan potensi. McCarthy (2014), menyatakan gejala stress pasca trauma menunjukkan pada peristiwa yang dirasakan membahayakan individu, saat individu dihadapkan pada situasi trauma, maka individu akan bereaksi baik secara psikologis maupun fisiologis. Sementara itu, menurut Barros-Bailey, Benshoff, dan Fischer (2009) trauma adalah suatu pengalaman emosional yang bersifat negatif dan dapat diprediksi secara biokimia, fisiologis, kognitif, dan perubahan perilaku terhadap traumafull event. Traumafull event bagi setiap individu 
adalah berbeda-beda. Traumafull event dapat memberikan pengaruh negatif pada individu yang mengalami. Traumafull event ini dapat membuat individu menjadi marah, tegang, bingung, dan cemas. Trauma ini dapat menurunkan sistem kekebalan tubuh (imun).

Matrone dan Leahy, (2005) mendefinisikan gangguan stress pasca trauma sebagai gangguan kecemasan akibat kejadian traumatis, seperti perang, pemerkosaan, dan bencana alam. Kejadian traumatis itu menyebabkan individu yang mengalami kejadian traumatisnya, menunjukkan gejalagejala seperti : (1) Merasa terus menerus mengalami kejadian traumatisnya atau tidak bisa menghilangkan kejadian traumatis meskipun peristiwanya sudah lampau; (2) Berkurangnya respon terhadap dunia luar; (3) Merasa asing terhadap orang lain; (4) mimpi buruk, mimpi kejadian traumatisnya secara terus menerus atau mengalami gangguan tidur.

Rumah yang hancur, harta benda yang rusak dan hanyut, kegiatan belajar yang terhambat dan lain-lain, inilah yang menjadi penyebab trauma anak gifted yang mengalami bencana rob dan banjir. Dan dan David, (2008) menyatakan emosi dan trauma psikologis dapat disebabkan oleh tamparan keras karena suatu peristiwa dalam satu waktu, misalnya kecelakaan yang mengerikan, bencana alam atau tindak kekerasan \& pelecehan seksual. Trauma juga dapat terjadi karena tekanan yang terus menerus, misalnya tinggal dilingkungan yang berpotensi bencana alam. Dampak peristiwa traumatik tentunya akan sangat mengganggu tugas perkembangan individu kedepannya apabila tidak ditangani secara tepat.

Dampak dari trauma bagi anak gifted menurut O'Brien dan Graham, (2009) adalah 1) dampak emosional seperti kaget, marah, sedih, mati rasa, merasa dihantui, bersalah, duka yang mendalam, terlalu perasa, merasa tidak berdaya, 'Tumpul' dan tak lagi mampu merasa senang serta bahagia dengan aktifitas sehari-harinya, disosiasi, berupa keberulangan dalam pikiran tentang bencana yang telah terjadi, merasa terpaku dan dikendalikan oleh kejadiankejadian, atau keterpakuan pada bencana, 2) dampak fisik seperti kelelahan fisik yang sangat besar, sulit atau bahkan tidak bisa tidur, gangguan tidur, sangat mudah tersentuh perasaan dan ingatannya, keluhan-keluhan yang mengarah pada gangguan syaraf, sakit kepala, reaksi-reaksi yang menggambarkan kegagalan sistem kekebalan tubuh, selera makan terganggu, libido meningkat atau justru menurun drastis, 3) dampak kognitif seperti sulit atau tak bisa lagi berkonsentrasi, tidak mampu membuat keputusan-keputusan, gangguan mengingat, sulit mempercayai informasiinformasi, kebingungan, mudah teralihkan atau perhatian mudah terpecah, Menurunnya penilaian terhadap keadaan diri, menurunnya penilaian terhadap kemampuan diri, menyalahkan diri sendiri, merasa mudah diganggu oleh pikiran ataupun ingatan, khawatir atau cemas.

Konseling individu logoterapi dianggap tepat untuk menemukan makna hidup anak gifted yang terkena bencana rob dan banjir karena di dalam konseling logoterapi terdapat dinamika spritual yang dikembangkan. Makna hidup merupakan motivator utama dalam kehidupannya, dan bukan rasionalisasi sekunder yang muncul karena dorongan-dorongan naluriahnya. Makna hidup ini merupakan sesuatu yang unik dan khusus artinya dia hanya bisa dipenuhi oleh orang yang bersangkutan, hanya dengan cara inilah dia bisa memiliki arti yang bisa memuaskan keinginan orang tersebut. 
Logoterapi adalah suatu jenis psikoterapi yang dikembangkan oleh Fiktor Emile Frankl (1905-1997), seorang neuropsikiater keturunan yang berasal dari Wina Austria yang pada tahun 1942 pernah ditahan oleh tentara Nazi ke dalam 4 kamp konsentrasi yang pada waktu itu dikenal sebagai kampkamp yang sangat berbahaya bagi nyawa seorang tahanan. Sehingga dari penderitaan yang dialami selama berada di dalam kamp kosentrasi Frankl menghasilkan sebuah karya psikoterapi yang pada saat ini menjadi salah satu pilar psikologi dan banyak diamalkan dalam dunia kesehatan maupun pendidikan yaitu logoterapi. Hal ini yang diperkuat penelitian yang dilakukan oleh Tremblay, Smith, Xie, dan Drake (2006) bahwa keefektifan konseling logoterapi untuk meningkatkan motivasi hidup. Hasil penelitian ini menyebutkan motivasi hidup manusia yang utama adalah mencari makna dapat dilakukan untuk korban banjir.

Logoterapi berasal dari bahasa yunani yang terdiri dari 2 kata yaitu kata "Logos" yang berarti makna (meaning) dan kerohanian (spiritually), dan kata "terapi" yang berarti pengobatan. Jadi, logoterapi adalah suatu psikoterapi yang mengakui adanya dimensi kerohanian pada manusia disamping dimensi ragawi dan kejiwaan serta beranggapan bahwa makna hidup (the meaning of life) dan hasrat untuk hidup bermakna (logoterapi)(the will to meaning) merupakan motivasi utama manusia guna meraih taraf kehidupan bermakna (the meaning life) yang diinginkan (Lustig \& Strauser, 2009). Logo terapi adalah psikoterapi pencarian makna hidup (logos) dalam kondisi apapun agar dapat bertahan dalam hidup

Logoterapy terbukti efektif untuk memberikan makna hidup orang yang mengalami keputusasaan. Terapi logoterapi mengusahakan agar kehidupan senantiasa berguna bagi diri sendiri, keluarga, masyarakat dan agama. Menurut penelitian ini logoterapi memiliki wawasan mengenai manusia yang berlandaskan tiga pilar filosofis yang satu dengan lainya erat hubunganya dan saling menunjang dalam menemukan makna hidup.

Hipotesis yang disampaikan dalam penelitian in adalah ada pengaruh logo terapi terhadap stres pasca trauma.

\section{METODE}

Penelitian ini menggunakan metode kuantitif. Rancangan penelitian yang digunakan penulis adalah penelitian quasi ekperimen. Desain ini terdiri dari satu kelompok eksperimen dan satu kelompok kontrol yang diberikan pretest, intervensi dan post test. Analisis data yang digunakan untuk melihat peningkatan makna hidup anak gifted yang mengalami gejala stress pasca trauma karena rob dan banjir. Subyek dalam penelitian ini adalah siswa yang berusia $10-15$ tahun sebanyak 10 siswa di Genuk, Sayung, Wringjajar, Morosari dan Kalisari.

\section{HASIL}

Berdasarkan analisis proses pelaksanaan konseling individu dengan teknik logoterapi yang dikembangkan serta hasil yang dicapai oleh klien membuktikan bahwa layanan konseling individu dengan teknik logoterapi efektif untuk meningkatkan makna hidup anak gifted yang trauma karena bencana rob dan banjir. Indikasi keberhasilan proses pelaksanaan layanan dapat dilihat dari peran yang dilaksanakan oleh konselor dan klien pada setiap tahapan, baik tahap attending sampai pengakhiran dimana pada tahap kegiatan konselor menerapkan tahap-tahap dari logoterapi sehingga terinternalisasi dengan baik terhadap klien. 
Efektivitas layanan dibuktikan dari hasil skala penerimaan yang menunjukan adanya peningkatan hasil evaluasi awal dan evaluasi akhir pada skor total penerimaan.

Peningkatan penerimaan anak gifted adalah sebesar 55 poin atau sama dengan $30,00 \%$. Berdasarkan hasil perhitungan uji Wilcoxon $\mathrm{Z}=-3.705$ dengan nilai signifikansi $\mathrm{p}=0,005(<$ $0,05)$ sehingga hipotesis diterima. Hal ini sejalan dengan Patterson (2009) yang menyebutkan bahwa konseling individu dengan teknik logoterapi efektif untuk meningkatkan makna hidup anak gifted yang mengalami gejala stress pasca trauma karena bencana rob dan banjir. Dengan melakukan kegiatan melalui permainan, media film, meditasi, drama, ibadah dan menghidupkan dinamika konseling efektif untuk meningkatkan penerimaan anak gifted di daerah bencana rob dan banjir. Semakin baik dalam memberikan layanan konseling individu dengan teknik logoterapi semakin baik pula penerimaan anak gifted di daerah bencana rob dan banjir. Konseling individu dengan teknik logoterapi melakukan kegiatan melalui permainan dan menghidupkan dinamika konseling yang merupakan intervensi yang efektif untuk meningkatkan penerimaan anak gifted trauma karena bencana.

Lustig dan Strauser, (2009) menyebutkan seorang anak gifted yang mengalami gejala stress pasca trauma karena bencana rob dan banjir seringkali menunjukkan reaksi emosional tertentu. Reaksi emosianal tersebut adalah shock, perasaan menolak keadaan, merasa sedih, cemas, marah dan sampai pada akhirnya dapat menyesuaikan diri dengan menerima keadaan. Keadaan ketika manusia dapat menyadari dan dapat menerima kondisi merupakan titik awal hasrat untuk hidup bermakna. Adanya hasrat untuk memiliki makna dalam hidupnya (logoterapi) akan membuat anak gifted mengisi hariharinya dengan kegiatan yang mempunyai manfaat untuk dirinya (Chan et al., 2008).

Hasrat untuk hidup bermakna (logoterapi) yang terpenuhi akan membawa kehidupan yang bermakna sehingga mendapatkan kebahagiaan walaupun anak gifted yang mengalami stress pasca trauma karena bencana banjir dan rob. Jika hasrat tersebut tidak dipenuhi maka anak gifted yang mengalami stress pasca trauma karena bencana banjir dan rob akan merasakan hidup yang tidak bermakna. Anak gifted yang mengalami gejala stress mengalami gejala stress pasca trauma karena bencana banjir dan rob yang dapat memahami makna hidupnya dan berusaha untuk membahagiakan dirinya sehingga akan jauh dari perasaan hampa dan putus asa dalam menjalani kehidupan sehari-hari (Tremblay et al., 2006).

Kebahagiaan yang didapatkan anak gifted yang trauma karena bencana banjir dan rob merupakan hasil dari usaha dan kerja keras yang dilakukannya dengan menjalankan kegiatan-kegiatan yang bermakna. Kebermaknaan hidup yang dirasakan anak gifted yang mengalami gejala stress pasca trauma karena bencana banjir dan rob tidak dicapainya dengan mudah, melainkan ada faktor-faktor pendukungnya. Faktorfaktor pendukung untuk meraih kebermaknaan hidup adalah adanya nilai-nilai daya cipta (kreatif), nilai penghayatan dan nilai bersikap. Nilai kreatif dapat ditunjukkan dengan melakukan kegiatan yang bermanfaat yaitu dengan bekerja, berkarya serta melaksanak giftedan tugas dengan sebaik-baiknya dengan penuh tanggung jawab (O’Brien \& Graham, 2009). 
Melalui bekerja dan berkarya seseorang dapat menemukan arti hidup dan menghayati kehidupan secara bermakna. Nilai-nilai penghayatan juga dapat mempengaruhi seseorang untuk dapat mencapai kebermaknaan hidup. Nilai-nilai penghayatan merupakan keyakinan dan penghayatan terhadap nilai-nilai kebenaran, kebajikan, keindahan, keimanan, keagamaan serta cinta kasih. Anak gifted yang mengalami gejala stress pasca trauma karena bencana banjir dan rob yang meyakini dan menghayati nilai-nilai tersebut dapat menjadikan kehidupan yang berarti. Faktor lain yang mendukung tercapainya kebermaknaan hidup adalah nilai-nilai bersikap, nilainilai bersikap ditandai dengan menerima dengan penuh ketabahan, kesabaran, dan keberanian dalam menerima segala bentuk penderitaan yang tidak dapat dihindari (Fatimah \& Fatimah, 2009).

Anak gifted yang mengalami gejala stress pasca trauma karena bencana banjir dan rob dapat dikatakan mempunyai kehidupan yang bermakna apabila ketiga komponen dari kebermaknaan hidup itu terpenuhi. Ketiga komponen itu adalah kebebasan berkehendak, hasrat untuk hidup bermakna (logoterapi) dan makna hidup. Anak gifted yang mengalami gejala stress pasca trauma karena bencana banjir dan rob mempunyai kebebasan untuk menentukan sikapnya, baik untuk dirinya, keluarganya dan bahkan untuk anak giftednya, kebebasan yang dilakukan tentunya disertai dengan tanggung jawab (Erwin, 2017).

Komponen yang pertama adalah kebebasan berkehendak. Anak gifted mengalami gejala stress pasca trauma karena bencana banjir dan rob juga memiliki kebebasan dan kemampuan untuk mengubah kondisi hidupnya untuk meraih kehidupan yang lebih berkualitas. Komponen selanjutnya adalah hasrat untuk hidup bermakna.
Hasrat untuk hidup bermakna (logoterapi) akan mendorong anak gifted yang stress pasca trauma karena bencana banjir dan rob untuk melakukan kegiatan agar kehidupan yang dijalaninya menjadi lebih berarti. Hasrat tersebut dapat dijadikan motivasi sehingga anak gifted yang mengalami gejala stress pasca trauma akan berusaha semaksimal mungkin memenuhi kebutuhan dirinya agar dapat berkembang dengan optimal sehingga dirinya dapat memaksimalkan kemampuan yang dimiliki. Komponen kebermaknaan hidup yang terakhir adalah makna hidup. Makna hidup akan memberikam nilai khusus bagi anak gifted yang trauma karena bencana banjir dan rob karena dengan adanya makna hidup maka anak gifted yang trauma karena bencana banjir dan rob akan mempunyai cita-cita, tujuan hidup yang jelas dan terarah untuk dirinya. Apabila makna hidup dapat terpenuhi dan merasakan kehidupan yang penuh arti maka akan mendapatkan kebahagiaan (Sutejo, 2009).

\section{SIMPULAN}

Konseling logoterapi adalah salah satu jenis strategi konseling yang dapat digunakan untuk mengatasi stress pasca peristiwa traumatik yang dialami individu pada saat bencana rob dan banjir. Konseling ini menjadi salah satu strategi yang perlu dipahami dan diimplementasikan oleh konselor di Indonesia untuk membantu anak gifted anak gifted korban rob dan banjir, mengingat faktor pemicu trauma saat ini semakin meningkat dan beragam. Dengan mampu menerapkan strategi ini pada anak gifted-anak gifted yang mengalami peristiwa traumatik, diharapkan kedepannya masalah perkembangan dan perilaku siswa akibat trauma akan semakin berkurang. Intervensi strategi dilakukan melalui konseling individu, dengan 4P yaitu : pembentukan hubungan, peralihan, penerapan strategi, pengakhiran. 
Rini Sugiarti: Logo Therapy Conselling for Gifted Children ...

\section{Ucapan Terima Kasih}

Ucapan terima kasih peneliti
haturkan kepada Bupati Demak,
Walikota Semarang, Dinas Pendidikan
Kabupaten Demak, Dinas Pendidikan
Kota Semarang, warga masyarakat
Genuk, Sayung, Wringjajar, Morosari
dan Kalisari; yang telah mendukung
penelitian ini, semoga penelitian ini
dapat bermanfaat bagi masyarakat.

\section{DAFTAR PUSTAKA}

Barros-Bailey, M., Benshoff, J. J., \& Fischer, J. (2009). Rehabilitation Counseling in the Year 2011. Rehabilitation Counseling Bulletin, 52(2), 107-113. https://doi.org/10.1177/003435520 8324262

Chan, Fong, Tarvydas, V.; Blalock, K. ;, Strauser, D. ;, \& Atkins, B. J. (2008). Unifying and Elevating Rehabilitation Counseling Through. Journal of Applied Rehabilitation Counseling Winter, 39(4), 114-120.

Dan, C., \& David, R. (2008). The Relationship Between a Counselor $\hat{a} €^{\mathrm{TM}} \mathrm{s}$ Education and Experience and the Time Spent on Tasks.

Fatimah, A., \& Fatimah, A. (2009). Telah disetujui oleh Tim Pembimbing: Pembimbing.

Indonesia, U., Keperawatan, F. I., \& Pascasarjana, P. (2009). Pengaruh Logoterapi..., Sutejo, FIK UI, 2009.

Lustig, D. C., \& Strauser, D. R. (2009). Rehabilitation Counseling Graduate Students' Preferences for Employment: Agreement Between Actual and Perceived Job Tasks of State--Federal Vocational Rehabilitation Counselors. Rehabilitation Counseling
Bulletin, 52(3), 179-188. https://doi.org/10.1177/003435520 8320932

Matrone, K. F., \& Leahy, M. J. (2005). The relationship between vocational rehabilitation client outcomes and rehabilitation counselor multicultural counseling competencies. Rehabilitation Counseling Bulletin, 48(4), 233244.

https://doi.org/10.1177/003435520 50480040401

McCarthy, A. K. (2014). Relationship between rehabilitation counselor efficacy for counseling skills and client outcomes. Journal of Rehabilitation, 80(2), 3-11.

O'Brien, M., \& Graham, M. (2009). Rehabilitation Counseling in the State or Federal Program. Rehabilitation Counseling Bulletin, 52(2), 124-128. Retrieved from http://flagship.luc.edu/login?url=ht tp://search.ebscohost.com/login.as $\mathrm{px}$ ?direct $=$ true $\& \mathrm{db}=\mathrm{ehh} \& \mathrm{AN}=356$ 48216\&site $=$ ehost-live

Patterson, J. B. (2009). Professional identity and the future of rehabilitation counseling. Rehabilitation Counseling Bulletin, 52(2), 129-132. https://doi.org/10.1177/003435520 8323949

Psikologi, F., Semarang, U., Logoterapi, T., \& Home, B. (2017). MENINGKATKAN PENERIMAAN ANAK BROKEN HOME Erwin Erlangga, 2(1), 1-6. 
Rini Sugiarti: Logo Therapy Conselling for Gifted Children ...

Tremblay, T., Smith, J., Xie, H., \&

Drake, R. E. (2006). Effect of

Benefits Counseling Services on

Employment Outcomes for People

With Psychiatric Disabilities.

Psychiatric Services, 57(6), 816-

821.

https://doi.org/10.1176/ps.2006.57

.6 .816

Wagner, C. C., \& Mcmahon, B. T.

(2004). Rehabilitation Counseling

Practice, (July 2017).

https://doi.org/10.1177/003435520

40470030401 